\title{
Epithelial-Mesenchymal Interactions for the Development of Intestinal Villi
}

\author{
Seunghoon $\mathrm{Oh}^{1}$ and ${ }^{\dagger}$ Young Bok Yoo ${ }^{2}$ \\ ${ }^{I}$ Dept. of Physiology, College of Medicine, Dankook University, Korea \\ ${ }^{2}$ Dept. of Anatomy, College of Medicine, Dankook University, Korea
}

\begin{abstract}
Small intestine has a structure called villi that increases the mucosal surface area for nutrient absorption. Intricate and tight epithelial-mesenchymal interactions are required for villi development. These interactions are regulated by signaling molecules, physical forces, and epithelial deformation. Signaling molecules include hedgehog (Hh), bone morphogenetic protein (BMP) and Wnt ligands. The Hh ligand is expressed from the epithelium and binds to the underlying mesenchymal cells, resulting in aggregation into mesenchymal clusters. The clusters express BMP and Wnt ligands to control its size and spacing between clusters. The clusters then form villi. Despite the fact that the villi formation is studied extensively, we do not have a complete understanding. In addition, the recent study shows there is a great relationship between the overexpression of the Hh signal and development of cancer in the gastrointestinal tract. Therefore, signaling between epithelial and mesenchymal cells and their physical interactions will be discussed on this review.
\end{abstract}

Key words : Epithelial-mesenchymal interactions, Intestinal villi, Hh, BMP, Wnt, Development

\section{INTRODUCTION}

The small intestine is a part of a digestive tract that is responsible for nutrient absorption. To maximize its function of absorption, small intestine has developed a folding structure called villi to increase the mucosal surface area. The villi, a small thin and finger-like projections of the small intestine, are composed of superficial simple columnar epithelium and deeper connective tissue which includes blood vessels, smooth muscles, nerves, and immune cells. The proliferation of the stem cell at the base of villi leads to regeneration of the epithelial lining every seven days (Cheng \& Leblond, 1974; Sato et al., 2009). When stem cells finish mitosis, the daughter cells push up the epithelium and differentiation takes place as they are proliferating along the villus. The epithelial cells at the tips of the villus undergo apoptosis and are removed from the epithelium.

An adult human has an average small intestine surface area of $30 \mathrm{~m}^{2}$. The villi increase the surface area as much as 6.5 times (Helander \& Fändriks, 2014). Nutrients from digested foods can be absorbed rapidly due to enormous surface area. Large loss of absorptive surface area inhibits the effective nutritional absorption and may result in lifethreatening nutrient deficiency such as malabsorption or intestinal failure (Goulet et al., 2004). When significant portion of the small intestine is removed, the increase in cell proliferation and migration helps the remaining intestine to build longer villi (Yang et al., 2004). The villi development only occurs in the fetus, and thus the villi number is unchanged after the neonatal stage (Clarke,

\footnotetext{
Manuscript received October 12, 2019, Received in revised form October 23, 2019, Accepted November 6, 2019

$\uparrow$ Corresponding Author : Young Bok Yoo, Dept. of Anatomy, College of Medicine, Dankook University, Chungnam 31116, Korea. Tel: +82-41-5503857, Fax: +82-41-559-7940, E-mail: ybyoo36@hanmail.net
}

This is an Open Access article distributed under the terms of the Creative Commons Attribution Non-Commercial License (http:// creative-commons.org/licenses/by-nc/3.0) which permits unrestricted non-commercial use, distribution, and reproduction in any medium, provided the original work is properly cited. 
1967; Forrester, 1972).

The development of villi starts at embryonic day (E) 14.5 in mice which is human fetus at $8-10$ weeks. The development occurs by morphogenesis, changing the structure of the pseudostratified epithelium into villi with simple columnar epithelial lining. The human and mice share similar intestine morphology and gene expression, therefore villi development of mice can be applied to the counterpart of human intestine. In mice embryo, the villi development begins in the duodenum and then spreads to the distal portion of small intestine within 36 hours (Goulet et al., 2004), and this phenomenon appears to be similar in the human intestine (de Bakker, 2016).

\section{Hh SIGNAL}

Villus development needs epithelial-mesenchymal interactions whose role has been highlighted for several decades. Epithelial-mesenchymal interactions is coordinated through signaling molecules such as hedgehog $(\mathrm{Hh})$, plateletderived growth factor (PDGF), bone morphogenetic protein (BMP) ligands, BMP signaling modifiers, Wnt and mechanical forces exerted by underlying tissue expansion and epithelial deformation (Wang et al., 2019). The proliferating epithelium secretes $\mathrm{Hh}$ and platelet-derived growth factor A (PDGFA). Hh signals bind mesenchymal cells, and help them to aggregate into clusters toward epithelial basement membrane (Madison et al., 2005; Kolterud et al., 2009; Walton et al., 2012).

Type of paracrine Hh signal, sonic hedgehog (Shh) and indian hedgehog (Ihh) signals are expressed by the nascent intestinal epithelium. The signals are then received by the mesenchymal cells, smooth muscle cells, endothelial cells, sub-epithelial, and myofibroblast (Ptch1-expressing subepithelial myofibroblast) that are located underneath the highly proliferative pseudostratified epithelium. The inhibition of the Hh signaling affects the villi patterning by expanding the desmin-positive smooth muscle progenitor cells and its mislocation (Madison et al., 2005). This expansion and mislocation increases the gene expression of the Tcf $4 / \beta$-catenin which increases the proliferation and the formation of the precrypt structures on villus tips (Brittan \& Wright, 2004).

Mice without Ihh show reduced proliferation in the intervillus region, indicating that Ihh is required to maintain the intestinal stem cells (Ramalho-Santos et al., 2000). Mice without Shh show an overgrowth of villi and there is a significant decrease in smooth muscle and the mice die after early somite stages (Ramalho-Santos et al., 2000). The requirements of Ihh and/or Shh for villi formation are further confirmed (Mao et al., 2010; Walton et al., 2012). Activation in Hh signaling leads to increase in size of villi clusters, and inhibition in Hh signaling prevents cluster to form (Madison et al., 2005; Kolterud et al., 2009; Walton et al., 2012). These results indicate that $\mathrm{Hh}$ signaling pathway is very important during villi development.

Mesenchymal cells express Foxf1 and Foxl1, Hh target genes (Madison et al., 2009). Inactivation of Foxf1 or Foxl1 lead to irregular villi (Kaestner et al., 1997; Ormestad et al., 2006), suggesting that the Hh function in the formation of villi is regulated partially by Foxf1 and Foxl1. It is also reported that the overexpression of the $\mathrm{Hh}$ signal can lead to cancer (Berman et al., 2003). The tumor is highly dependent on Hh ligand. The tumor growth is stimulated with autocrine $\mathrm{Hh}$ signaling instead of paracrine that was seen in villi formation (Berman et al., 2003).

The Hh signal helps to create mesenchymal clusters that are arranged in a specific pattern, but the mechanism of the cluster distribution is unknown (Walton et al., 2012). After the formation of the initial cluster, the position of the secondary, tertiary, and quaternary clusters will be established according to its previous specific patterning field. The formation of the subsequent cluster is positioned in the intervillus regions, between the two villi, when the region is large enough for the expansion of the patterning field. The intestinal villi clusters form first in the anterior, dorsal, 
and then towards posterior and lateral region (Breathnach, 1978).

Mesenchymal cells express many Hh target genes such as Gli1, Ptc1 (Ptch1) and PDGFR $\alpha$, a receptor for the (PDGFA), before villi formation (Walton et al., 2012). Villus morphogenesis is partially coordinated through epithelial secretion which stimulates mesenchymal condensation, proliferation, and invagination of overlying epithelium to form villi (Karlsson et al., 2000). The cluster cells contain PDGFR $\alpha$ and the epithelial cells express PDGFA ligand. The loss of either the PDGFR $\alpha$ or PDGFA ligand does not change initiating clusters but inhibit subsequent clusters. The malfunction of the PDGFA ligand leads to deformed and sparse villi and the spacing between the clusters is controlled by the PDGFA ligand. These suggest both $\mathrm{Hh}$ and PDGF signals are coordinated to control this mesenchyme-induced process (Karlsson et al., 2000).

When epithelial stem cells isolated from adult mouse intestine are cultured, they fail to grow villi, indicating epithelial stem cells alone do not have an ability to develop to form villi without mesenchymal cells (Sato et al., 2009). There is intimately tight interdependence between mesenchymal cells and the epithelial cells.

\section{BMP SIGNAL}

The space between the clusters are usually 60-70 $\mu \mathrm{m}$ in mice (Walton et al., 2012). After the mesenchymal clusters are formed, villi emergence takes place (Walton et al., 2016). Several different types of BMP ligands are expressed by the Hh-responsive mesenchymal cells of clusters (Karlsson et al., 2000). The BMP ligands bind the cluster cells itself for regulating the cluster patterning such as the size and spacing of the clusters (Walton et al., 2016). The BMP signals are also used to regulate overlying epithelium, resulting in deformation and exit the cell cycle, and inhibit the cell proliferation at the tips of the villi (Wang, 2019).

A high concentration of BMP can inhibit cluster formation. Even after the cluster formation, a change in BMP concentration can have an effect on the cluster patterning (Walton et al., 2016). When BMP receptors are genetically deleted from the Hh-responsive mesenchymal cells or BMP inhibitor are added gradually, the cluster spot pattern turn into stripe, indicating the BMP has a function of regulating the cluster structure (Walton et al., 2016). This change in cluster pattern supports the Turing field, a reaction-diffusion model that shows the distribution and patterning of the mesenchymal clusters. This model was first suggested by a mathematician Alan Turing (Turing, 1952).

\section{Wnt SIGNAL}

The Wnt ligand is secreted by mesenchymal cells and epithelial cells (Theodosiou \& Tabin, 2003; Wang et al., 2018). The Wnt signaling controls both the proliferation and differentiation in the crypt-villus axis and is used for crypt formation in intervillus regions (Van de Wetering et al., 2002; Madison et al., 2005).

When Wnt is interrupted, epithelial proliferation is significantly reduced due to decrease in Myc expression and increase in p21 (cell cycle inhibitor) expression (Madison et al., 2005). A Wnt transcriptional effector, Tcf4, is required for making and maintaining the crypt stem cell (Madison et al., 2005). Inhibition of the Tcf4 can lead to fewer villi and reduced proliferation in intervillus regions (Korinek et al., 1998). Before villi formation, thick pseudostratified epithelium is not able to express Wnt signals. After villi emerge, cluster mesenchymal cells express BMP, which repress Wnt signaling in the overlying epithelium on the clusters, confining Wnt signals to the intervillus regions (Chin et al., 2016; Nigmatullina et al., 2017).

With several BMP ligands and BMP signaling modifiers, Wnt molecules regulate cluster patterning and give the information to the overlying epithelium, which can deform 
and exit from the cell cycle (Wang et al., 2019).

\section{PHYSICAL FORCE}

In mice, overlying epithelial cells on the cluster receive several signals from underlying cluster and change shape, shortening apicobasaly. Cell shape change evokes intraepithelial compression force at the intervillus regions between clusters. Intraepithelial physical constraint and mitosis deform the overlying epithelium to initiate apical surface invaginations, changing thick pseudostratified epithelial layer into villi (Freddo et al., 2016). However, no direct evidence showing the relationship between physical force and signaling molecule has not been elucidated yet.

Unlike mammals, chick's intestinal villi are formed by using physical force with the signaling molecules (Freddo et al., 2016). The physical force is generated by the smooth muscle layer which is located in the deep mesenchyme. As the smooth muscle cells differentiate, a compressive force is generated on the intestine. As the circular muscles, exterior longitudinal muscles, then the interior longitudinal muscles are differentiated in series, more and more physical constraint is given to the intestine (Shyer et al., 2013). The smooth muscle layer affects the epithelial structure to curve (Shyer et al., 2015). The curvature of the epithelium leads to zig-zag pattern formation and finally into villi structure (Shyer et al., 2013). At the 'valley' of the zig-zag, mesenchymal clusters are formed due to $\mathrm{Hh}$ signal produced by the epithelial cells (Shyer et al., 2015).

\section{CONCLUSION}

Inter-tissue communication can be possible for villi development, as epithelial-mesenchymal interactions are, on the background of close contact between two tissues, tightly coordinated through soluble signaling molecules, physical forces by expanding tissue and following epithelial deformation (Fig. 1). Overlying epithelium secretes $\mathrm{Hh}$

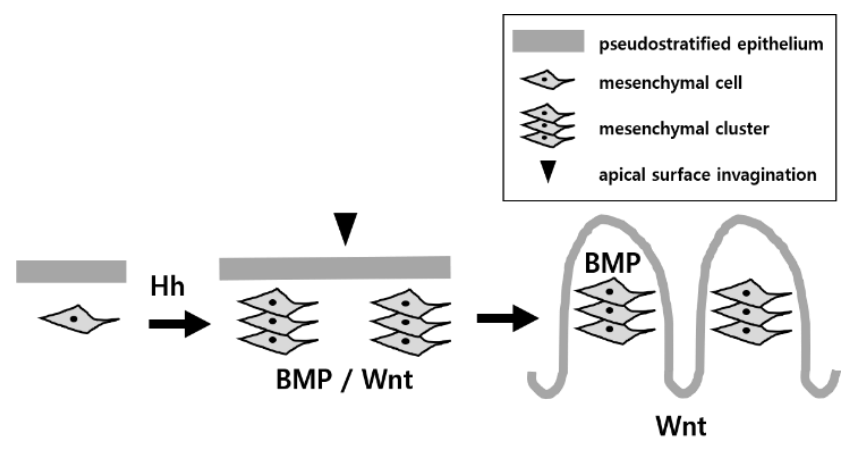

Fig. 1. Schematic diagram showing the villi development. Pseudostratified epithelium releases hedgehog $(\mathrm{Hh})$ to mesenchymal cells, resulting in the formation of mesenchymal clusters. The clusters then express bone morphogenetic protein (BMP) and Wnt ligands to regulate its pattern. Epithelial invagination occurs at the site between clusters. This deformation of epithelium is triggered by intraepithelial pressure and mitosis, resulting in changing thick pseudostratified epithelial layer into villi. BMP regulates epithelium at the tip of villus while Wnt ligands work for crypt formation.

ligands including several signals to the underlying mesenchymal cells that aggregate into cluster, which express BMP affecting its own cluster patterning and deforming back overlying epithelium for initiating villi, and Wnt affecting cluster patterning and controlling the proliferation and differentiation of overlying epithelium for establishing crypt-villus axis. The deforming epithelium generates intraepithelial compression pressure to initiate apical surface invaginations, changing pseudostratified epithelial layer into villi. In chick, the physical force from the sequentially developing smooth muscle layers, causes the epithelium to deform, forming villi. The cellular and molecular drivers of the villus formation have been extensively studied, but it is not completely understood in mammals.

It is interesting to know a recent finding that the overexpression of the Hh signal can lead to cancer. The tumor growth is stimulated with autocrine Hh signaling instead of paracrine that was seen in villi development. 
Therefore, it is worth to aim future research on the treatment of gastrointestinal cancer by targeting the $\mathrm{Hh}$ signal.

\section{ORCID}

\author{
Seunghoon $\mathrm{Oh}$ \\ https://orcid.org/0000-0002-1203-5011
}

Young Bok Yoo

https://orcid.org/0000-0002-3302-2543

\section{CONFLICT OF INTEREST}

The authors declare no potential conflict of interest.

\section{AUTHOR CONTRIBUTIONS}

Conceptualization: Oh S, Yoo YB.

Data curation: Oh S, Yoo YB.

Formal analysis: Oh S, Yoo YB.

Methodology: Oh S, Yoo YB.

Software: Oh S, Yoo YB.

Validation: Oh S, Yoo YB.

Investigation: Oh S, Yoo YB.

Writing - original draft: Oh S, Yoo YB.

Writing - review \& editing: Oh S, Yoo YB.

\section{ETHICS APPROVAL}

This article does not require IRB/IACUC approval because there are no human and animal participants.

\section{REFERENCES}

Berman DM, Karhadkar SS, Maitra A, Montes de Oca R,
Gerstenblith MR, Briggs K, Parker AR, Shimada Y, Eshleman JR, Watkins DN, Beachy PA (2003) Widespread requirement for Hedgehog ligand stimulation in growth of digestive tract tumours. Nature 425:846-851.

Breathnach AS (1978) Development and differentiation of dermal cells in man. J Invest Dermatol 71:2-8.

Brittan M, Wright NA (2004) The gastrointestinal stem cell. Cell Prolif 37:35-53.

Cheng H, Leblond CP (1974) Origin, differentiation and renewal of the four main epithelial cell types in the mouse small intestine I. Columnar cell. Am J Anat 141:461-479.

Chin AM, Tsai YH, Finkbeiner SR, Nagy MS, Walker EM, Ethen NJ, Williams BO, Battle MA, Spence JR (2016) A dynamic WNT/beta-CATENIN signaling environment leads to WNT-independent and WNTdependent proliferation of embryonic intestinal progenitor cells. Stem Cell Reports 7:826-839.

Clarke R (1967) On the constancy of the number of villi in the duodenum of the postembryonic domestic fowl. J Embryol Exp Morphol 17:131-138.

de Bakker BS, de Jong KH, Hagoort J, de Bree K, Besselink CT, de Kanter FE, Veldhuis T, Bais B, Schildmeijer R, Ruijter JM, Oostra RJ, Christoffels VM, Moorman AF (2016) An interactive threedimensional digital atlas and quantitative database of human development. Science 354:aag0053.

Forrester JM (1972) The number of villi in rat's jejunum and ileum: Effect of normal growth, partial enterectomy, and tube feeding. J Anat 111:283-291.

Freddo AM, Shoffner SK, Shao Y, Taniguchi K, Grosse AS, Guysinger MN, Wang S, Rudraraju S, Margolis B, Garikipati K, Schnell S, Gumucio DL (2016) Coordination of signaling and tissue mechanics during morphogenesis of murine intestinal villi: A role for mitotic cell rounding. Integr Biol (Camb) 8:918-928.

Goulet O, Ruemmele F, Lacaille F, Colomb V (2004) Irreversible intestinal failure. J Pediatr Gastroenterol 
Nutr 38:250-269.

Helander HF, Fandriks L (2014) Surface area of the digestive tract: Revisited. Scand J Gastroenterol 49:681-689.

Kaestner KH, Silberg DG, Traber PG, Schütz G (1997) The mesenchymal winged helix transcription factor Fkh6 is required for the control of gastrointestinal proliferation and differentiation. Genes Dev 11:15831595.

Karlsson L, Lindahl P, Heath JK, Betsholtz C (2000) Abnormal gastrointestinal development in PDGF-A and PDGFR-(alpha) deficient mice implicates a novel mesenchymal structure with putative instructive properties in villus morphogenesis. Development 127:3457-3466.

Kolterud A, Grosse AS, Zacharias WJ, Walton KD, Kretovich KE, Madison BB, Waghray M, Ferris JE, $\mathrm{Hu}$ C, Merchant JL, Dlugosz AA, Kottmann AH, Gumucio DL (2009) Paracrine Hedgehog signaling in stomach and intestine: New roles for hedgehog in gastrointestinal patterning. Gastroenterology 137:618628.

Korinek V, Barker N, Moerer P, Van Donselaar E, Huls G, Peters PJ, Clevers H (1998) Depletion of epithelial stem-cell compartments in the small intestine of mice lacking Tcf-4. Nat Genet 19:379-383.

Madison BB, Braunstein K, Kuizon E, Portman K, Qiao XT, Gumucio DL (2005) Epithelial hedgehog signals pattern the intestinal crypt-villus axis. Development 132:279-289.

Madison BB, McKenna LB, Dolson D, Epstein DJ, Kaestner KH (2009) FoxF1 and FoxL1 link hedgehog signaling and the control of epithelial proliferation in the developing stomach and intestine. J Biol Chem 284:5936-5944.

Mao J, Kim BM, Rajurkar M, Shivdasani RA, McMahon AP (2010) Hedgehog signaling controls mesenchymal growth in the developing mammalian digestive tract.
Development 137:1721-1729.

Nigmatullina L, Norkin M, Dzama MM, Messner B, Sayols S, Soshnikova N (2017) Id2 controls specification of $\mathrm{Lgr}^{+}$intestinal stem cell progenitors during gut development. EMBO J 36:869-885.

Ormestad M, Astorga J, Landgren H, Wang T, Johansson BR, Miura N, Carlsson P (2006) Foxf1 and Foxf2 control murine gut development by limiting mesenchymal Wnt signaling and promoting extracellular matrix production. Development 133:833-843.

Ramalho-Santos M, Melton DA, McMahon AP (2000) Hedgehog signals regulate multiple aspects of gastrointestinal development. Development 127:27632772.

Sato T, Vries RG, Snippert HJ, van de Wetering M, Barker N, Stange DE, van Es JH, Abo A, Kujala P, Peters PJ, Clevers H (2009) Single Lgr5 stem cells build cryptvillus structures in vitro without a mesenchymal niche. Nature 459:262-265.

Shyer AE, Tallinen T, Nerurkar NL, Wei Z, Gil ES, Kaplan DL, Tabin CJ, Mahadevan L (2013) Villification: How the gut gets its villi. Science 342:212-218.

Shyer AE, Huycke TR, Lee C, Mahadevan L, Tabin CJ (2015) Bending gradients: How the intestinal stem cell gets its home. Cell 161:569-580.

Theodosiou NA, Tabin CJ (2003) Wnt signaling during development of the gastrointestinal tract. Dev Biol 259:258-271.

Turing AM (1952) The chemical basis of morphogenesis. Phil Trans R Soc B Biol Sci 237:37-72.

Van de Wetering M, Sancho E, Verweij C, De Lau W, Oving I, Hurlstone A, Van der Horn K, Batlle E, Coudreuse D, Haramis AP, Tjon-Pon-Fong M, Moerer P, van den Born M, Soete G, Pals S, Eilers M, Medema R, Clevers H (2002) The beta-catenin/TCF-4 complex imposes a crypt progenitor phenotype on colorectal cancer cells. Cell 111:241-250.

Walton KD, Kolterud A, Czerwinski MJ, Bell MJ, Prakash 
A, Kushwaha J, Grosse AS, Schnell S, Gumucio DL (2012) Hedgehog-responsive mesenchymal clusters direct patterning and emergence of intestinal villi. Proc Natl Acad Sci USA 109:15817-15822.

Walton KD, Whidden M, Kolterud A, Shoffner SK, Czerwinski MJ, Kushwaha J, Parmar N, Chandhrasekhar D, Freddo AM, Schnell S, Gumucio DL (2016) Villification in the mouse: BMP signals control intestinal villus patterning. Development 143:427-436.

Wang S, Cebrian C, Schnell S, Gumucio DL (2018) Radial WNT5A-guided post-mitotic filopodial pathfinding is critical for midgut tube elongation. Dev Cell 46:173188.

Wang S, Walton KD, Gumucio DL (2019) Signals and forces shaping organogenesis of the small intestine. In: Wellik DM (ed), Organ Development. Academic Press, New York, pp 31-66.

Yang H, Antony PA, Wildhaber BE, Teitelbaum DH (2004) Intestinal intraepithelial lymphocyte gamma delta-T cell-derived keratinocyte growth factor modulates epithelial growth in the mouse. J Immunol 172:41514158. 